\title{
Syntactic Aspects of Poetry: A Pragmatic Perspective
}

\author{
Dr. Khalil Hassan Nofal \\ Head of Department of English, Director of Language Centre \\ Philadelphia University, Jordan \\ E-mail: nofalk48@yahoo.com,knofal@Philadelphia.edu.jo
}

$\begin{array}{lr}\text { Received: July 11, } 2011 \quad \text { Accepted: September 11, } 2011 \quad \text { Published: February 1, } 2012 \\ \text { doi:10.5539/ass.v8n2p221 } & \text { URL: http://dx.doi.org/10.5539/ass.v8n2p221 }\end{array}$

\begin{abstract}
The language of poetry is different from the language of other literary genres. That is to say, the grammar of poetry is different. This refers to the fact that the rules of grammars will have to be modified so as to permit certain "liberties" or "licenses" on the one hand, and to account for the novel kinds of restrictions that are imposed on linguistic units in poetry both within and beyond the sentence, on the other. Such grammar would reveal, by a comparison with the grammar of the ordinary language, many differences between poetic language, the ordinary language and any literary genre. Therefore, literature particularly poetry cannot be examined apart from language. Accordingly, poetry cannot be grasped without a thorough knowledge of grammar.
\end{abstract}

Keywords: Linguistic, Aspects, Poetry, Pragmatic, Perspective

\section{Introduction}

This paper is meant to review some studies and analyses that deal with the language of poetry as it is different from the language of other literary genres. Poetry consists of language that produces effects ordinary language does not produce. So poetry is a language differently ordered or arranged. Levin (1969) pointed out that linguistic analysis, when applied to poetry, would result in a grammar that is different from the grammar that a linguistic analysis of ordinary language would produce (11).

The language of poetry differs drastically from ordinary discourse. Many of these differences derive from certain literary conventions. In other words, many features distinguishing poetry from ordinary discourse result from the mere fact that a writer addresses himself to writing a poem. This fact entails a considerable number and variety of linguistic particularities. The conventions of the poetic form entail features like rhyme, alliteration, meter and so on (Levin 59).

\section{Types of Deviations in the Language of Poetry}

Leech (1969) argues that any deviation from expected patterns of linguistic behavior will bring about a reaction of disorientation and surprise. Rules in poetry, Leech elaborates, are made to be broken (10-12). Leech observed that looking back over the span of English literature since Chaucer; we note that certain freedoms of language have been traditionally sanctioned in verse, but not in prose (17-23). Leech remarked:

The obvious function of these freedoms is to compensate the poet for his loss of freedom in submitting himself to the discipline of verse composition; to furnish him with a wider set of choices than are normally available in English and thus to give him a better chance of squeezing his language into a predetermined mould of versification (18).

\subsection{Lexical Deviation (violation of lexical rules of word formation)}

Neologism, or the invention of new words, is one of the more obvious ways in which a poet exceeds the normal resources of the language. Leech calls new words "nonce-formations" if they are made for the nonce, i.e., for a single occasion only (42). The English rule of word formation permits prefixation of "fore-" to a verb, to convey the meaning "beforehand" as in foresee, foreknow, foretell and forewarn. If this rule were completely free in its application, we would use verbs such as foresell (sell in advance) or foreappear (appear in advance) without even noticing their oddity. But the rule is in fact limited to a small group of vocabulary items. For instance, in "The Waste Land" T.S. Eliot augments the group by using the verb "foresuffered" in the line: 
1). And I Tiresias have foresuffered all ("The Waste Land" 243).

This strikes us as a novelty and as a surprising extension of the expressive possibilities of the language. Leech maintains that "Eliot's "foresuffered" is not just a new word, but the encapsulation of a newly formulated idea: that it is possible to anticipate mystically the suffering of the future just as it is possible to foresee, foretell, or have foreknowledge of future events (44). Forming new words using affixes is another process used by poets. For examples Eliot invented "unflowering.

2). And growing between them, indifference

Being between two lives - unflowering, between

The live and the dead nettle ("Little Gidding" III: 4-7).

Jeffries (1993) contends that poets are sometimes influenced by spoken language in their lexical choices. The influence may be from a number of different sources. It may be, for example, the choice of a poet to use a regionally distinct vocabulary or vocabulary that is clearly colloquial, possibly even slang or taboo (31). The reasons why poets make such choices are also varied; the desire to escape from a standard language which is seen as oppressive, the wish to use a spoken style for certain characters in poems, and the intention to shock readers by using vocabulary that is not often seen in print. Other poets challenge reader's expectations about lexical selection, for example, by using words assigned to one syntactic class as if they were members of another, for instance the rhetorical figure known as anthimeria. Thus "did" and "didn't" act as nouns in e. cumming's line "he sang his didn't he danced did", and "grief" becomes a temporal expression in Dylan Thomas's "a grief ago."

\subsection{Syntactic Deviation}

Jeffries (1993) argues that poets have not hesitated to use a grammar which reflects everyday usage or the cultural background of the poet (35). Jeffries evidence is that Kofi Anyidoho, in his poem "My Mailman Friend was Here", uses a grammatical structure typical of a West African pidgin. For example, "I go write you something small again" has a verb phrase form which differs from the standard English am going to write, and this is followed by a pronoun you which in standard English would be introduced by a preposition "to" as it is an indirect object. Minor sentences, sentences without a finite verb, are one way that poets vary their grammatical structures. Both of the following examples are from "Canticle for Good Friday" by Geoffrey Hill. The first consists of a NP not followed by a verb of any kind,

3). A clamping cold-figured day

while, the second contains subject and complement but no verb to create a full sentence.

4). He, as yet unsearched, unscratched

The effect of avoiding using main verbs in poetry may be used to render the poem timeless, thus achieving the purpose of not anchoring the action in a particular time span. Leech (1969:45) cites another syntactic violation in English poetry i.e., the successive genitives in Hopkins' "The Wreck of the Deutschland" as in the following example:

5). Our hearts' charity's hearth's fire, our thought's chivalry's throng's lord.

Moreover, word order, as mentioned in George M. Landon's article (1968:194-200) is a syntactic violation. He proposes the view that sentences such as(6a) and (7a) below exhibiting an unusual word order may be described as violating certain rules which would have yielded the corresponding, sequentially well-formed sentences (6b) and (7b).

6). a. Our sons their fathers' failing language see (Pope).

b. Our sons see their fathers' failing language.

7). a. By them had slimy paths been trailed and scraped (Owen)

b. Slimy paths had been trailed and scraped by them.

Along the same line of argument, another freedom poets have enjoyed by custom is the arranging of syntactic elements in an irregular order (hyperbaton). Jumbled clause structures have been taken so much for granted in verse. The opening two stanzas of Cowper's "The Diverting History of John Gilpin" contain three examples:

8). John Giloin was a citizen

Of credit and renown, 
Of famous London town

John Gilpin's spouse said to her dear,

Though wedded we have been

These twice ten tedious years; yet we

No holiday have seen.

The sections in bold italics each contains the main clause elements subject (s), verbal (v), and object/complement (c), which in prose, as in ordinary speech, would almost certainly occur in the order SVC. Cowper gives us three separate variations of that order: CVS, CSV, and SCV.

Furthermore, poetic language may violate or deviate from the generally observed rules of the language in many ways, i.e., word order, pleonasm, ellipses. Word order includes fronting, postponement and passivization. See (Brook, 1958, Leech, 1969; Roscow, 1981; Traugott, 1972; Dillon, 1975 and Dillon, 1976). These processes characterize the unusualness of syntax in poetry. In fact, most of them could be viewed as a relaxation of the constraints on transformations in Modern English (i.e. licenses), (cf. Dillon, 1975).

Most of the rules of Modern English that front constituents are used by poets: topicalization, left dislocation, Prep. P-fronting, adjective phrase-preposing. PP-fronting and NP-fronting are frequently applied to the same sentence, usually leaving the verb in clause-final position. Interestingly, the usual order of application seems to be NP-, then PP-fronting, so that Od immediately precedes the subject as in the following line:

9). In golden chains the willing world she draws (Pope).

10). But since like slaves his bed they did ascent (Dryden).

The following examples illustrate inversion:

Cs $\mathrm{v} \quad \mathrm{s}$

11). Vain is her wish. (Wordsworth)

Adv

$\mathrm{V} \mathrm{s}$

12). After many a summer dies the swan (Tennyson).

$\mathrm{O}$

V S V

13). Full many a glorious morning have I seen (Shakespeare)

In the aforementioned examples, when the subject complement (adjective), the time adverbial, and the direct object are fronted, all of these optionally trigger subject / verb inversion in poetry .

Eliot's poetry and Chaucer's poetry among others will be used as illustrative examples of all types of deviation. The Language in most of Eliot's poems is not only audacious, but lacking in intelligible connections. As a verbal impressionist, he flouts traditional syntax by introducing phrases that appear to have no grammatical functions. The fragmentary style results from terse, conversational sentences. This is very noticeable in "Gerontion". (Partridge 1976: 141):

14). I was neither at the hot gates

Nor fought in the warm rain

Nor knee deep in salt marsh, heaving a cutlass

Bitten by flies, fought

Partridge states "In its compression, Eliot's syntax is simpler than that of any other modern poets (181). The difficulties that arise result from the impressionistic fragments of thought and inadequate use of stops to signal their relationships. For example, this can be illustrated in lines (21-3) of "Animula" quoted underneath:

15). The pain of living and the drug of dreams

Curl up the small soul in the window seat

Behind the Encyclopaedia Britannica

Additionally, Partridge argues that the style in which "Journey of the Maji" is written is modeled on biblical prose, with much phrasal coordination, and many participial constructions taking the place of clauses. (183). In the lines quoted underneath from "Journey of the Maji" three participial lines are initiated by the preposition "with:" 
16). With the voices singing in our ears

With a running stream and a water-mill

With an alien people clutching their gods

It may be maintained that emphasis can be given to new or important information by making sure that it occurs towards the end of the sentence or clause. This is information structure. For example, in the opening line quoted underneath from "The Hollow Men," Eliot uses a quite normal order of clause elements:

17). Subject: We

Verb: are

Complement: the hollow men (1)

The length of the complement here is an indication of its information value in the clause. It may be called end weight for the purpose of emphasis. Wright (1965) contends that Eliot's poetry is full of "figures of repetition" or parallelism (93-100). For instance, Eliot extensively uses "anaphora" in which a word or phrase is repeated at the beginning of successive lines in the same poem. Eliot extensively makes use of these figures of speech to support a tone of monotony, a sudden dramatic moment, or an ironic linkage of apparently different elements.

Anaphora, frequently used by Eliot, can be employed to build up an impression of grandeur by the measured emphasis of the figure of parallelism, (Halliday and Hasan 1976:4; Leech, 1969:80; Ust D.2000; Wright 1965). In the lines quoted below from T.S Eliot's "The Waste Land" and Mathew Arnold's "Thyrsis" both poets respectively use anaphora to show parallelism.

18). After the torchlight red on sweaty faces

After the frosty silence in the gardens

After the agony in stony places ("The Waste Land" 322-4)

19). Too quick despair, wherefore with thou go?

Soon will the high Midsummer pomp's come on,

Soon will the musk carnations break and swell,

Soon shall we have gold - dusted snapdragon, ("Thyrsis" 1-4)

In both poems the anaphora is highly effective; it is evocative and gives a haunting force to the feeling. The reader also gets a physical impression of getting lost.

Another figure of speech extensively and frequently used in Eliot's poetry is epistrophe or ploce; a rhetorical term for the repetition of a word or phrase at the end of successive clauses. Also known as epiphora. An example of this rhetorical term is cited in the lines quoted below from Eliot's "Marina":

20). Those who sharpen the tooth of the dog, meaning Death

Those who glitter with the glory of hummingbird, meaning Death

Those who sit in the style of contentment, meaning Death

Those who suffer the ecstasy of animal, meaning Death ("Marina" 6-3).

Another rhetorical figure used in Eliot's poetry is symploce which entails a repetition that combines an anaphora and an epistrophe in which the first and last word or words in one phrase, clause, or sentence are repeated in one or more successive phrases, clauses, or sentences. An example of symploce can be cited from the two lines quoted underneath from Eliot's Prufrock:

21). The yellow fog that ...........upon the window panes

The yellow smoke that ...... on the window panes ("Prufrock" 15-16)

Another effect of repetition, is the repetition of a few words in the same emotional context and hence with the same significance. The use of empty in the lines quoted underneath from Eliot's "The Waste Land" illustrates this, in all its appearances, the same sense of desolation sometimes mixed with triviality is present ( Wright 1965:202)

22). a. The river bears no empty bottles, sandwich ("The Waste Land" 178)

b. And voices singing out of empty cisterns and exhausted wells ("The Waste land" 385).

c. There is the empty chapel, only the wind's home("The Waste Land" 389)

d. In our empty rooms ("The Waste Land" 410) 
23) a. Greet was the feeste in Atthenes that day (KnT: 2483).

b. Greet is my wo " guod she, and sighte soore (TrT: 897) .

c. Greet was the prees that swarmeth to and fro (SgT: 189).

d. Greet was the wo the knight hadde in his thought (WBT: 1083).

The mildly emphatic nature of the fronting of adjectives may be judged from Chaucer's frequent use of the adjective "greet" in front position.

Some poets opt to use foregrounding to defamiliarize the content of their poetry. According to Katie Wales in her Dictionary of Stylistics, foregrounding "is essentially a dynamic process and one which aims for defamiliarizing for making strange. Foregrounding may be accomplished by the use of deviant or ungrammatical constructions. Patterns formed by the repetition of similar items will be more common and more noticeable in poetry than in other kinds of language. (Culler, 2002:60) "(See Stylistic Variants below). This is usually made to focus on certain features of the language, (the poetic language in particular) to make them more prominent, or highlighted in order to convey certain messages. Some poets may also deviate from the normal order of constituents or may repeat certain items not only to convey certain message, but also to achieve a certain rhythm and / or rhyme. So in the first stanza of Herbert's poem "Virtue" quoted underneath the adjective phrase of the first line is foreground by syntactic repetition.

\section{4). Sweet day. So cold, so calm, so bright,}

The bridal of the earth and skie:

The dew shall weep thy fall to night

For thou must die

The syntactic repetition of the adjective phrase in the first line, in addition to its denotation, carries over to the reader the feelings of the poet of the atmosphere which he happened to be in and to give his messages a further weight. In the lines quoted above the poet employed alliteration combined with assonance, the thing which impresses the reader and helps him imprint such adjectives in his memory.

Sentence fragments are acceptable in current poetic language, typically unacceptable in most genres of English prose. Sentence fragments thus mark one of the grammatically identifiable differences between poetic and non-poetic language (Katz, 1997).

Eliot, in particular, is famous for using fragmentation in his poetry. For instance, Eliot's use of fragmentation in "The Waste Land" operates on three levels: first, to parallel the broken society and relationship the poem portrays; second, to deconstruct the reader's familiar context, creating an individualized sense of disconnection; and third, to challenge the reader to seek meaning in mere fragments, in this "enigmatic" poem as well as in a fractious world, (cf, Hilligoss, 1998).

Eliot's fragments produce the same effect in his descriptions of broken relationships, particularly in "A Game of Chess". The fragments in this section - mostly in the form of conversation- illustrate the strained communication and consequent emotional tension of a relationship gone sour. This is evident in the following conversation between a woman and a man.

25). My nerves are bad tonight. Yes, bad. Stay with me

Speak to me. Why do you never speak. Speak.

What are you thinking of? What thinking? What?

I never know what you are thinking. Think.

I think we are in rats' alley.

Where the dead men lost their bones.

What is that noise?

The wind under the door.

"What is the noise now? What is the wind doing"

Nothing again nothing. ("The Waste Land" 111 -20) 
According to Hilligoss, the primary function of fragmentation in poetry is to send the reader an active, personal quest for meaning, both in the poem itself and in the world it portrays. This process can be difficult, as Eliot subtly implies in the poem's famous opening lines.

26). April is the cruelest month, breeding

Lilacs out of dead land, mixing

Memory and desire, stirring

Dull roots with spring rain.

Winter kept us warm, covering

Earth in forgetful snow, feeding

A little life with dried tubers. ("The Waste Land" 1-7)

Ironically this passage associates April, a springtime month, a time of regeneration and renewal- with cruelty. The alleged cruelty of April is the same as Eliot's cruelty in constructing an enigmatic poem from the fragments of his culture. "The Waste Land" concludes with a message of hope, delivered by the voice of the thunder. What the thunder says is simply a fragment: DA, which is interpreted to mean three things: datta, (to give alms) dayadhvan (to have compassion), and damyata (to practice self control), (Abrams 1979: 283). To quote Hilligoss on this matter: "Just as the natural cycle of the reasons described in the above opening lines does not end with wintry death, even fragments - fragmented words, people or cultures - can be given new life, a rebirth into something whole" ( ibid).

Eliot's poems employ fragments in an imagist manner, simply juxtaposing phrases and requiring the reader to discover the relationship among those fragments. Fragments are also often used to set a scene as in the first section of "Preludes" where Eliot uses NP fragments in the third, fourth and final lines (Katz 1997):

27). The winter evening settles down

With smell of steats in passgeways

\section{Six o'clock.}

The burnt -out of smoky day

And now a gusty shower craps

The grimy scraps

Of withered leaves about your feet

And newspapers from vacant lots;

The showers beat

On broken blinds and chimney-pots,

And at the corner of the street

A lonely cab-horse steams and stamps.

And then the lighting of the lamps. (1 - 13)

28). They looking back, all th' eastern side behold

Of Paradise, so late their happie seat,

Waved over by that flaming brand, the gate

With dreadful faces thronged and fiery arms;

Some natural tears they dropped, but wiped them soon;

The world was all before them, where to choose

Their place of rest, and Providence their guide:

They hand in hand, with wandering steps and slow,

Through Eden took their solitary way

(Paradise Lost, Book 12: 64-649, John Milton) 
In an article entitled "The Poetic Use of Sentence Fragments" Seth R. Katz states that the poet uses fragments to imitate and so to make an assertion about the nature of human perception. Katz maintains that perception consists of fragments that we assemble into meaningful wholes. Moreover, by orating a poem out of a great pile of fragments, the poet asserts that we perceive the world by collecting many bits of experience and drawing relationships among them. From the relationships we discover within that collection, we abstract and understand the world.

Another characteristic of poetic language is that it is full of tropes. Tropes are among the most inventive in poetry (Partridge 1976:149). Tropes are divided into the following categories:

1. Metonymy: is a figure of speech that uses a concept closely related to the thing actually meant. The substitution makes the analogy more vivid and meaningful. In other words, it is a figure of speech in which the poet substitutes a word normally associated with something for the term usually naming that thing. For Example, "big-sky country" for western Canada (Lancashire, 2002). Are examples of metonymy are:

29). But the hand!

The boy's first outcry was a rueful laugh,

As he swung towards them holding up the hand

Half in appeal, but half as if to keep

The life from spilling. (Range - Finding: 18 -22) (Frost "Out, out-").

The literal meaning is to keep the blood spilling. These lines tell us that the hand is bleeding and the boy's life is in ganger (danger).

30). History has many cunning passages, contrived corridors. (Gerontion: 14)

2. Simile: a figure of speech in which a comparison is expressed by the specific use of word or a phrase such as like, as, than, seem or Frost's favorite "as if (See 29 above)". (Lancashire 2002). Examples of similes are found in the following examples:

31). Let us go then, you and I,

While the evening is spread out against the sky,

Like a patient etherized upon a table ... (Eliot's Prufrock: 1-3)

In this simile, Eliot launches a beautiful image to compare "the evening which is spread out against the sky "with a patient etherized upon a table." Figuratively speaking, the image seems to be striking since "the evening" (the end of the day ) is ,quite often, used as a symbol of a patient ( the end of life ). Taking this figurative image from a pragmatic angle, the reader may understand that the poet wants to convey a message to us that each one of us should die exactly as "the evening" should vanish.

32). I wandered lonely as a cloud

That floats on high, o'er vales and hills ("The Daffodils" 1-2)

It can be easily noticed that Wordsworth uses a simile by comparing himself to a cloud moving aimlessly and heading to nowhere in the sky. It is certainly an eye catching image to be flying over hills and valleys in such a splendid nature where beautiful daffodils are happily dancing under the trees and beside a lovely lake. Pragmatically speaking, the poet wants to convey a message to the reader that he will be quite happy if he could enjoy nature, quite far from the artificial world (See example 34 below ).

3. Personification: "an anthropomorphic figure of speech where the poet describes an abstraction, a thing, or a non-human form as if it were a person. William Blake's "Rose, thou art sick!" is an example." In other words, personification is an ontological metaphor in which a thing or abstraction is represented as a person. The following lines of poetry are examples of personification:

33). Of restless nights in one-night cheap hotels (Prufrock 6)

34). And that was my long scythe whispering to the ground (Frost "Mowing" 2).

35). When all at once I saw a crowd,

A host, of golden daffodils,

Besides the lake, beneath the trees,

Fluttering and dancing in the breeze (Daffodils: 3-6) 
Wales K. in her Dictionary of Stylistics defines personification as "a figure of speech or trope in which an inanimate object, animate non-human or abstract quality is given human attributes." As an example of this figure of speech is encountered in "The Daffodils" when Wordsworth, while wandering as a cloud in the sky, sees a host of daffodils as a group of cheerful people happily dancing in the breeze. The most striking analogy is the comparison of Daffodils to dancing humans. Pragmatically speaking, the setting in which the dancing takes place, affects the reader's interpretation of the poet's message to a great extent, especially when he / she finds himself / herself in the middle of a beautiful nature, joining very happy people at a very exciting party .

4. Metaphor: A figure of speech in which a comparison is made between two things essentially unlike. To Frost, metaphor is really what poetry is about. He is notably a poet of metaphors more than anything else. Metaphor is a comparison that is made literally either by a verb (for example, John Keats' "Beauty is truth, truth beauty" from his "Ode on a Crecian Urn" or, less obviously, by a combination of adjective and noun, noun and verb, etc. For example, Shakespeare's sonnet on the "the marriage of true minds", but in any case without pointing out a similarity by using words as "as", "like", or "than". In this context, the writer can put his ideas and thoughts into words or containers, and then send them along a channel or conduit to a listener or reader who takes that idea or thought out of the container and makes meaning of it. The following are examples of metaphors:

36). To have squeezed the universe into a ball (Eliot's "Prufrock": 92)

37). The world is unwedded garden

That grows to seed; things and gross in natural (Shakespeare's Hamlet)

38). She is as in field a silken tent

At midday when a sunny summer breeze

Has dried the dew and all it's rops relent, (Frost's "The Silken Tent" 1-3).

(A woman is admired for her strength and beauty like a silken tent.)

Figuratively speaking, Eliot and Shakespeare draw this analogy by employing such powerful metaphors probably to reveal their literary competence on the one hand, and / or to catch the eye of the reader and gain his internal and appreciation on the other. A pragmatic approach to metaphor requires a keen perception of the structure of registers in terms of lexical sets and subset representing smaller conceptual fields. A metaphor results when we conceive a certain kind of experience in terms of another. (Sharme 2009:32)

5. Images (imagery): "an expression that describes a literal sensation, whether of hearing, seeing, touching, tasting, and feeling." (Lancashire 2002). James Dixon (1976) illustrates the following examples from "Journey of the Maji"

39). "Beating the darkness"

can refer to the triumph and victory of Christ.

40). "White horse"

is perhaps a reference to the militaristic and conquering Christ of revelation? or the horse is a symbolic of the death of paganism under the onslaught of Christianity.

6. Irony: is a figure of speech when an expression used is the opposite of the thought in the speaker's mind, thus conveying a meaning that contradicts the literal definition. "It is stating something by saying another quite different thing, sometimes it's opposite (Lancashire 2000). Another important feature of Eliot's technique is his constant use of a certain form of irony, a style known as "romantic irony" or "the irony of instant deflation" (Johnston, I. 1999). The most famous example of this is the line from Prufrock. The speaker knows that he will tell the old story "with a sigh" of a choice that "made all of the difference"

41). I have measured out my life in coffee spoons (Prufrock: 51)

"The first six words lead us to expect, at last, some significant insight into something- the rhetorical build up in the language promises something significant; the prosaic last three words indicate an immediate deflation." , (ibid).

42). I shall be telling this with a sigh

Somewhere ages and ages hence:

Two roads diverged in a word, and I

Took the one less travelled by, 
And that has made all the difference.

(Robert Frost's "The Road not Taken" 15-20).

While the effect is more important than the cause, most metaphors begin with some type of syntactic deviance, and because of the close relation between syntax and semantics, almost all creative uses of syntactic deviance have strong semantic effects (Cureton 1986, Halliday 1985). Syntactic structures can be extended, deepened, repeated, broken, inverted, interlaced, truncated, and so forth. All these formal arrangements then can serve as analogues of experience in some other mode (emotional perceptual, volitional, ... etc.

\subsection{Stylistic Variants}

Leech (1969) defines stylistics as "the study of literary style or the study of the use in literature, the language of particular writer, a particular period, a particular genre, even a particular poem" (1). Therefore, as pointed out above it may be supposed that literature cannot be examined apart from language any more than language can be studied apart from literature. That is to say, a literary work cannot be properly understood without a thorough knowledge of the language, which is its medium of expression. Each register has its own characteristic style with certain lexical and grammatical choices. Poets, particularly modern ones, have successfully freed themselves from constraints of what is so called "poetic language." (Sharma 2009:31).

The major stylistic variants in poetry to produce marked structures are (i) word order (fronting, postponement and discontinuity), (ii) pleonasm, (iii) ellipsis, and (iv) passivization.

\subsection{Word order}

In poetry, word order may be shifted around to meet emphasis, to heighten the connection between two words, or to pick up on specific implication. Moreover, word order may convey an emotional, psychological and spiritual impact. Word order will be treated in terms of (i) fronting, (ii) postponement and (iii) discontinuity.

\subsection{Fronting}

Fronting is the term that applies to instances of stylistic movement in which an element of a given structure is extracted from its normal / unmarked position (in the middle or end of that structure) and placed in an unusual/ marked position. The examples listed below show that four types of sentence constituents can be fronted, namely (i) obligatory adjunct, (ii) optional adjunct, (iii) direct object and (iv) object complement. Each of these constituents is separately handled below:

\section{(i) Obligatory Adjunct Fronting}

Examples of obligatory adjunct fronting can be seen in the following sentences:

43). a Here is no water but only rock (Eliot's "The Waste Land" 331)

44). a. At the first turning of the third stair

Was a slotted window bellied like the fig's fruit ("Ash-Wednesday" 114-5)

45). a In my beginning is my end. (East Coker:1)

46). a On hunting be they ridden roially, (KnT: 1682).

It is noted that the adverbs in the above examples, which function as obligatory adjuncts are moved from their final / unmarked positions to initial / marked positions. This is to say that when the above sentences retrieve their unmarked forms, they read as follows.

43). b. No water is here but only rock.

44). b. A slotted window bellied like the fig's fruit

Was at the end of the first turning of the third stair

45). b. My end is in my beginning

46). b. They be ridden roially on hunting

On the other hand, all the instances of obligatory adjunct fronting in the data are accompanied by subject-verb inversion whenever the subject is a category other than a personal pronoun. It is worth noting that only finite verb phrases are involved in subject-verb inversion concomitant to fronting of obligatory adjuncts. Moreover, only main clauses incorporate this type of fronting provided that the verb is intensive and with the meaning of existence or appearance.

\section{(ii) Optional Adjunct Fronting}


Adverbials in general are characterized by a type of positional mobility that is not typical of other types of sentence constituents. Fronting of optional adjuncts occur a lot in poetry in general and in Eliot's in particular. Examples are:

47). By the waters of Leman I sat down and wept （"The Waste Land" 182)

48). In the room the women come and go ("Prufrock" 13)

49). Here we go round the prickly pear ("The Hollow Men" 68)

50). Under a juniper-tree the bones sang ("Ash-Wednesday" 91)

51). Into the temple when they sholde gon ("Sum.T" 1846)

52). In pious times, e're priestcraft did begin

Before polygamy won made a sin;

("Absolom and Architophel" 1-2) (John Dryden)

In these examples, the adverbials are moved from their unmarked positions (sentence finally) to a marked position at the opening of the sentences. Due to the fact that adjuncts can be stacked, it is possible to front the optional adjunct occurring in a given structure as can be seen in the following example, where three such adjuncts are fronted:

53). In this decayed hole among the mountains

In the faint moonlight, the glass is singing. ("The Waste Land" 385-6)

The difference between fronting of obligatory adjuncts and fronting of optional adjuncts is that the former is usually accompanied by SV inversion, whereas the latter does not involve any kind of inversion. Both obligatory and optional fronting used as a matter of front focus.

\section{(iii) Direct Object Fronting}

The direct object fronting can be witnessed in the following examples:

54). These fragments I have shored against my ruins (Eliot's "The Waste Land" 430)

55). Eyes I dare not meet in dreams. (Eliot's"The Hollow Men" 19)

56). Ten thousands saw I at a glance

Tossing their heads in sprightly dance (Wordsworth "Daffodils" 11-12).

Wordsworth, not only shifts the direct object "ten thousands" to the front of the sentence, but also inverts the subject and the verb to say "saw I " instead of using the normal grammatical order "I saw". Poets, generally speaking, have the right to rearrange words in the order they may apt to. However, poets might have used that poetic language for the sake of rhyme and rhythm on the one hand, and/or to exercise their poetical licenses on the other. From a pragmatic perspective, however, Wordsworth, by using the above unfamiliar word order, has highlighted and given prominence to the object (ten thousands daffodils). This, in effect, means that the information message conveyed by the structure "Ten thousands saw I at a glance", the poet's words are significantly different from the message conveyed by the sentence: I saw ten thousands at a glance, which is the normal grammatical order.

\section{(vi) Verb Fronting}

The following are illustrative examples:

57). Still falls the Rain

Dark as the world of man, black as our loss

Blind as the nineteen hundred and forty nails

Upon the Cross. (Edith Sitwell "Still Falls the Rain" 1-4)

58). Swelleth the brest of Arcite and the soore ("KnT" 2743).

59). Ran Colle oure dogge, and Tablot and Garland ("NPT":3383)

It is worth noting that the inversion in the above examples is contextually appropriate and it also serves a practical function in avoiding the "top-heaviness" of structure in sentences having an extended compound subject. Functionally, the process of SV inversion is used for the purpose of end-focus and end- weight.

60). Herde al this thyng Criseyde well inough ("Tr ii" 1590 ). 
In the above example, the inverted order VOS is presumably simply a metrical matter, because neither herde nor the vague phrase al this thyng is sufficiently trenchant to call for emphatic positioning at the beginning of the line.

\section{(v) Adjective Fronting}

Adjective Fronting is frequently used in English poetry-particularly the adjectives that function as subject attribute:

61). So smooth, so sweet, so silvery, is thy voice.

(Upon Julla's Voice: 1. Robert Herrick)

62). Calm is the morn without a sound, (Tennyson "In Memoriam" 1)

63). Fair is her cottage in its place (Tennyson)

The requirements of rhyme also play their part in determining Chaucer's word order. The positioning of adjectives is often determined by rhyme. Chaucer allows himself considerable freedom in this, as the following examples illustrate:

64). And she was cleped madane Eglentyne

Ful well she song the service dyvyne. ("Gen. Prol" 121-122)

65). That was upon the carpenter's wal.

He syngeth in his voys gentil and small. (Mill $\mathrm{T}: 3359-3360$ ).

The adjective fronting may be a very common feature of Chaucer's descriptive verse:

66). Short was his gowne, with sleeves long and wyde ("Gen. Prol" 93).

67). Discreet he was and of greet reference ("Gen. Prol" 312).

68). Embrouded was he, as it were a meede ("Gen. Prol" 89).

69). Wynsynge she was, as is a joly colt (Mill T: 363)

The adjective fronting in the above examples, the variation in placing the pronominal subject alone with a front shifted participate or adjective is governed by the principle of avoiding heavy stress on the pronoun. Moreover, it can be easily noted that we find complete inversion exists as illustrated in (67-69), besides no inversion exists where the participle draws the pronominal subject next to it, as illustrated in (66-68).

\section{(iv) Object Complement Fronting}

The following is a self-explanatory example:

70). Who then made strong the fountains and made fresh the

spring Made cool the dry rock and made firm the sand ("Ash-Wednesday"135-6)

To conclude the syntactic analysis of fronting in general, the following notes can be pointed out:

1. Fronting is an optional syntactic movement operating most usually on post-verbal constituents in a sentence / clause.

2. When fronting operates on an obligatory adjunct, SVI (provided that the subject is not a personal pronoun) often becomes the norm rather than the exception.

3. Fronting optional adjuncts does not usually induce (SVI).

4. The type of sentence constituents that is most susceptible to fronting is the optional adjunct.

\subsection{Postponement}

Postponement refers to a syntactic movement transformation whereby a constituent is extracted from its normal position in the unmarked structure, and moved to the right to occupy a marked position in the derived structure. Postponement can operate on three types of constituents, namely (i) direct object, (ii) notional subject, and (iii) adjectives.

\section{(i) Postponed Direct Object}

Postponed direct objects are the most common type of postponed sentence constituents in Eliot's poetry. Postponement of direct object occurs in the type of sentence pattern [SVOA]. The type of verb occurring in the pattern is often labeled complex transitive verb (Quirk et al. 1985:54). Examples are: 
s $\quad \mathrm{A} \quad \mathrm{Adv} \quad \mathrm{Od}$

71). And you see behind every face the mental emptiness

deepen Leaving only the rowing terror ("East Coker"124-5)

s v Adv

72). I turned and saw below

od

The same shape twisted on the banister ("Ash-Wednesday"101-2)

s(she) $\quad \mathrm{v} \quad \mathrm{Adv}$

73). $\Delta \quad$ Gives too late

od

What is not believed in , or still believed ("Gerontion" 40-1)

$\mathrm{s}$

74). I Tiresias, though blind, throbbing between two lives,

V

Old man with wrinkled female breasts, can see

Adv

od

At the violet hour, the evening hour that strives

Homeward, and brings the sailor home from sea,

The typist home at teatime, clears her breakfast, lights

Her stove, and lays out food in tins. ("The Waste Land" 218-33)

It can be argued that the direct object postponement provided in the above examples are motivated by two requirements, viz (i) placement of elements of heavier informational content sentence finally, and (ii) avoidance of clumsiness or oddity of expression. Witness of oddity ( 74 above), which results when the 4-word adverbial at the violet hour, is placed after the 30 -word direct object NP the evening hour ... in tins.

(end -weight principle )

\section{(ii) Postponed Notional Subject (Extraposed Subject).}

Notional subject postponement is a syntactic transformation whereby the notional subject of the existential there construction is transposed rightward to be placed immediately after the verb.

$$
\text { v s }
$$

75). There rises the hidden laughter

$$
\text { Of children in the foliage (Burnt Norton:178-9) }
$$

76). In the juvescence of the year

\section{$\mathbf{v}$ \\ s \\ Came Christ the tiger (Gerontion:19-20)}

77). Out of the window perilously spread

$\mathbf{s}$

Her drying combinations touched by the sun's last rays (The Waste Land:224-5)

It can be easily noted that the verbs in the above examples are all intransitive and of fairly general "preventative meaning": verbs of motion (rise, come, spread).

\section{(iii) Postponed Adjectives}

Adjectives are postponed in Eliot's poetry probably for the purpose of end-focus. These postponed adjective function as object complements. The following is a self-explanatory example:

78). I have seen them riding seaward on the waves 
Combing the white hair of the waves blown black

When the wind blows the water white and black

We have lingered in the chambers of the sea

By sea-girls wreathed with seaward red and brown

Till human voices wake us, and we drown. ("Prufrock" 126-131)

\subsection{Discontinuity (Broken Order)}

Discontinuity is the separation of closely related words and phrases in a clause or sentence. The forms of discontinuous modification in poetry are (i) broken order of subjects, (ii) broken order of verbs and (iii) postponement of relative clauses. The following are representative examples:

79). So we moved, and they, in a formal pattern, ("Burnt Norton" 33)

80). Should I, after tea and cakes and ices

Have the strength to force the moment to it's crisis? ("Prufrock" 79-80)

81). And they were behind us reflected in the pool ("Burnt Norton" 40)

82). I said to my soul, be still, and let the dark come upon

you which shall be the darkness of God. ("East Coker" 113-4)

83). And smale foweles maken melody,

That slepen at the nyght with open eye ("Gen. Prol" 9).

Examples (82-83) above are of discontinuous modification in Eliot's and Chaucer's poetry, the separation of a relative clause from its antecedent. This illustrates a general tendency of English in all periods "to reverse the final position for more complex parts of a clause or a sentence- the principle of end-weight" (Quirk et.al. 1985:410).

84). by Mr Silvero

With caressing hands, at Limoges

Who walked all night in the next room. ("Gerontion" 23-5)

85). Housbonds at chirche dore she hadde fyve

Withouten oother compaingnye in youthe,

But thereof nedeth to speke as nowthe ("Gen. Prol" 460-3).

Broken order in (85) is a special form of discontinuity in which the separated elements are co-ordinates. The separation of the parts of a sentence is often for the sake of rhyme, (Elliot 1974:75). The broken order of subjects may be used to satisfy metrical requirements and generally to secure balance and emphasis (Roscow 1981:22).

86). Er that dye, sorwe have he and shame ("CY Prol":709).

This is an example of broken order of objects.

87). To lyve with hire and dye, and by hire stoned ("MLT":245).

This is an example of broken order of verbs.

88). ful longe were his legges and ful lene ("Gen Prol":59).

89). As hoot he was and lecherous as a sparwe ("Gen Prol" :626).

Examples (88-89) of broken adjectives functioning as subject complements. Moreover, it is worth mentioning that when the subject is impersonal, there is S-Aux inversion, and when the subjects is personal, the verb follows it in normal order. The subject noun phrases in sentence (79) are separated by a verb phrase. In sentences (80) and (81) the verb phrases are separated by adjuncts. In sentences (82) and (83) the discontinuous modification is the separation of the relative clauses from their antecedent. This may be to reserve the final position for the more complex parts of a clause or sentence - the principle of end-weight.

\subsection{Pleonasm}

Eliot's poetry contains the following examples of pleonasm:

90). That corpse you planted last year in your garden 
Has it begun to sprout? ("The Waste Land" 71-2)

91). OOOO that Shakepeherian $\boldsymbol{R a g}-$

It's so elegant ("The Waste Land" 128-9)

92). Eyes I dare not meet in dreams

In death's dreams kingdom

These do not appear. ("The Hollow Men" 20-2)

In the above examples, pleonasm is embodied in the repetition of the subject by means of personal pronouns it in (90) and (91), whereas it is embodied in the repetition of an object by means of a demonstrative pronoun in (92). Pleonasm in Eliot's poetry may be used to reinforce the structure of the sentence and to secure special effect such as emphasis. Moreover, there are three other examples, where the personal pronoun precedes the subject:

93). He the young man carbuncular arrives. ("The Waste Land" 231)

94). Up roos he Julius, the conqueror ("MKT": 2673).

95). His officers with swifte feet they renne ("KnT": 2868).

96). Had they deceived us.

Or deceived themselves, the quiet-voiced elders, ("East Coker" 77-80)

97). Aleyn the clerk, that herde this melody,

He poked John, and seyde, "slepesstow "? ("RvT": 4168).

It is noted that the subject and the pronoun in $(93,94 \& 95)$ lie within a single line, but within two lines in $(96 \&$ 97). A rough distinction can be made between close or "emphatic repetition" when a pleonastic pronoun directly follows or precedes the $\mathrm{HN}$ or is separated from it by only a few words, and distant or "structural repetition" when a pleonastic pronoun is separated from the HN by a longer sequence of words (Elliot 1974:51; Kerkhof 1982: 235; Mustanoja 1966:135; Roscow 1981: 67) .

Additionally, the following examples show that Eliot extensively uses repetition of phrases and clauses for the purpose of reinforcement of meaning.

98). O dark dark dark. They all go into the dark.

The vacant interstellar spaces, the vacant into the vacant,

The captains, merchant bankers, eminent men of letters ("East Coker" 102-4)

99). Lord, I am not worthy

Lord, I am not worthy ("Ash - Wednesday":124-5).

100). I grow old .... I grow old (Prufrock: 120)

Eliot wants to stress through this repetition the fact that the world of "The Waste Land" has become a world that can be readily labeled as morally fragile and trivial.

\subsection{Ellipsis}

Ellipsis enables the abbreviation of sentences by omitting elements that are retrievable from the context. In colloquial speech, which poets in general extensively use, ellipsis gives precision and brevity. The stylistic variety of ellipsis in poetry includes (i) ellipsis of subject pronoun (ii) ellipsis of the copula "be", (iii) ellipsis of lexical verbs, (iv) ellipsis of subject pronoun plus the copula be and (v) ellipsis of relative pronoun plus the copula $\boldsymbol{b e}$. The following are representative examples:

it

101). And what she gives, $\triangle$ gives with such supple confusions

she

That the giving famishes the craving. $\Delta$ Gives too late

What's not believed in, or is still believed; ("Gerontion" 39-41)

102). And syen the fox toward the grove gon,

he

103). And $\triangle$ bar upon his bak the cok away ("NPT": 3378 ) . 
are

is

104). Your arms $\Delta$ full, and your hair $\Delta$ wet ("The Waste Land":38)

is

105). But this $\triangle$ his tale, which that ye may here ("Cl.T" :50) .

moved

106). So we moved, and they $\Delta$, in a formal pattern, ("Burnt Norton" 33)

go

107). Thou shalt $\triangle$ with me to helle yet to-nyght ("FrT":16.36)

adorn

108). Now leaves $\Delta$ the trees, and flowers adorn the ground (Pope "Spring" :43)

109). And I have known the arms already, known them all

Arms that are bracelet and white and bare.

they are

But in the lamplight, $\Delta \quad \Delta$ downed with light brown hair! ("Prufrock": 63-5)

110). Out of the window perilously spread

which were

Her drying combinations $\Delta$ touched by the sun's last rays ("The Waste Land":224-5)

who

111). With hym ther was a plowman $\Delta$ was his brother ("Gen Prol": 529 )

2.10 Passivization

Passive constructions in poetry incorporate two types, namely: (i) agentive passive, and (ii) agentless passive.

2.10.1 Agentive Passive

The agentive passive constructions in poetry incorporate two semantic classes of agents, viz (i) human agent and

(ii) inanimate agent. The two types are exemplified respectively in the following sentences:

112). Undisciplined squads of emotion. And what there is to conquer

By strength and submission, has already been discovered

Once or twice, or several times, by men whom one can not

Hope ("Four Quartets"; "East Coker":188:92).

113). And eek I pray Jhesu shorte his lyves.

That noght wol be governed by hir wyves ("WBT": 1262 )

114). And ben converted from hire wikked werkes ("TC1":1005)

115). ...Unnatural vices

Are fathered by heroism. Virtues

Are forced upon us by our impudent crimes ("Gerontion":45-7).

On the other hand, a survey of Chaucer's and Eliot's poetry on the agent passive gives rise to the following:

1. When the logical subject is mentioned, it is found in the prepositional adjunct opening with "by", "from" "of" or "with". Examples are:

116). And the pool was filled with water out of sunlight.

("Four Quartets", "Burnt Norton":37).

117). With many a tempest hadde his berd been shake. ("Gen.Prol":405)

118). And ben converted from hire wikked werkes.

Through grace of God ("TCI":1005).

119). Of his proverbs n'of his olde sawe,

Ne I wolde nat of hym corrected be ("WBT":661) 
120)...... The word in the desert

Is most attacked by voices of temptation, ("Four Quartets", "Burnt Norton":163-4)

121). These tears are shaken from the wrath-bearing tree ("Gerontion":48)

2. It has been noticed that the most common preposition used to link the agent to the passive sentence is "by". The preposition "by" is replaced by "with" or "from" when the agent is an inanimate entity.

3. The grammatical subject of the passive always corresponds to the direct object of the active form as in all examples quoted above. The use of the subject of the passive corresponding to that of indirect object of the active form is rare:

122). Here $\boldsymbol{I}$ am an old man in a dry month.

Being read to by a boy, waiting for rain. ("Gerontion": 1-2)

4. Some instances of the prepositions "from" and "with" in the passive constructions should be interpreted instrumentally rather than agentively, as in examples (116) and (117) quoted above.

\subsubsection{Agentless Passive}

Agentless passive in poetry is much more frequently used than agentive passive. In many cases, there is no logical subject because it is either (i) redundant where the deleted agent can be inferred from the situational contexts, (ii) unknown, where the speaker is uncertain of the identity of the doer of the action. Moreover, the use of agentless passive sentences is justified on the ground that the identification of the agent is less important than the action itself. That is the most important is not also who did something, but what was done and who is " done - to ". Examples are:

123). When the evening is spread out against they sky ("Prufrock":2)

124). How shal the world be served? ("Gen. Prol":187) .

125). My cousin's, he took me out on a sled,

And I was frightened. He said, Marie, ("The Waste Land":14-5)

126). Who shal be slayen or elles deed for love ("KnT": 2038).

127). The river tent is broken ....

The nymphs are departed. ("The Waste Land":173-5).

Agentless passive constructions may be divided into "actional passives" which express actions and "statal passives" which express state:

128). The houses are all gone under the sea

The dancers are all gone under the hill ("Four Quartets", "East Coker": 100-1)

129). Will the veiled sister between the slender

Yew trees pray for those who offend her

And are terrified and can not surrender ("Ash-Wednesday" 190-2)

The agent is probably deleted because the actions are more significant than the persons who performed such actions. The syntax of poetry is flexible then. There is of course an intimate connection between syntax and style, and it is impossible to make a sharp distinction between the two. Word order frequently becomes the vehicle for different stylistic aims- emphasis, irony, rhetorical flourishes and the like.

\section{Conclusion}

To conclude, it is expedient to sum up the major characteristics of poetic language in general:

1). The use of complex language which often refuses traditional syntax, grammar and punctuation. That is, poetic language is marked, particularly in word order. The word order is irregular or hyperbaton.

2). Employment of loose syntax. Poetic language is influenced by spoken language. "Poetry is a return to common speech". It is characterized by its use of flagrantly prosy and vulgar aspects of everyday usage. The syntax of poetry tends to be loose and illogical and to bear a closer resemblance to the structure of spoken conversational language. Therefore, the loose syntax can be characterized as colloquial.

3). Creation of imagery is an essential feature of poetry as well as the tropes of semantic transfer; repetition or parallelism, metaphor, metonymy, heaps of images, simile, personification and irony and musical devices such as alliteration and assonance. That is rhetoric is allowed to take the place of syntax, for it is concerned with rearrangement of words to produce an effect of sound and meaning rather than with the correct syntax of the 
language or even the logical arrangement of thoughts. Thus, the use of rhetoric and the absence of a strict norm or English grammar go hand in hand.

4). The use of foregrounding as the aesthetically intentional distortion of the linguistic components is another feature of poetry. Moreover, the word's freedom from its habitual referent invokes its potential freedom to combine with an enormous number of referents.

5). The use of neologism and archaism characterize poetic language. That is, poets are not restricted to the language of their own particular period.

6). Modification of Grammar. The rules of grammar are modified in the poetic language as it permits certain licenses and to account for novel kinds of restriction that are imposed on linguistic units in poetry. Rules in poetry are made to be broken for the purpose of disorientation and surprise. Poets utilize lexical, grammatical and semantic deviations.

7). Sentence structure and phrase structure in the poetic language is different from those of any literary genre and is similar to those of spoken code. Poets permit themselves considerable freedom in word order for certain purposes, e.g. emphasis, front focus, end-focus, end-weight or rhyme... etc, for syntax is similar to that of the spoken language.

8). Usually, structure movement operates on sentence constituents and phrase constituents. Moreover, syntactic movement aims at thematization which is generally carried out optionally in the language of poetry. That is poets permit themselves considerable freedom in word order for different purposes. Both fronting and postponement generally conform to the general communication norms of the English sentence, whereby old and/or light information precedes new and / or heavy information in the poetic sentence.

9). It may be generalized that poets employ the phenomena of discontinuity and broken order that involve subjects, objects, adjectives, and verbs. Pleonasm is a characteristic feature of poetry. Pleonasm involves the repetition of the subject and object by means of personal or demonstrative pronouns. Ellipsis is another chrematistic feature of poetry. Poets generally use subject pronoun deletion, copula be deletion, lexical verb deletion and relative pronoun deletion.

10). Passive constructions, agentive and agentless, are frequently used in poetry. The most common preposition used in poetry is "by" which can sometimes be replaced by "with", "from " and "of", particularly when the agent is an inanimate noun phrase. The agentless passive is mainly targeted at thematizing the subject. In doing so, the agentless passive may be viewed as fronting type of syntactic movement. In contrast, the agentive passive is mainly aimed at giving end-focus to the postponed agent, particularly when such an agent is a heavy / complex NP. This entails that the agentive passive can be regarded as postponement movement.

11). Figures of speech such as metaphor, simile and personification are extensively used in poetry as expressive devices through which images, visual as well as autitory are evoked through one "object" with another. Poets quite often, consciously or subconsciously, employ devices of this kind to prove their literary competence on the one hand, and to give their messages a stronger impact on the reader/ hearer. Poets may wish, by using images of kind, to prove a particular atmosphere in which both the reader and the poet share similar feelings and experiences, i.e. their viewpoints towards the world.

12). From a pragmatic perspective, however, the poet may wish to carry over to the readers / hearer a particular message which is not actually embodied in the references of the individual words. In fact, in the sum of the references of the individual words of the message. Every word has a meaning every time, and in every context it is used. The reader / hearer, on his part, may give the message different interpretations depending on a variety of factors, social, psychological and whatever feeling and mood he may have at that particular moment.

\section{Pedagogical Implications}

Although this paper is linguistically descriptive and is not pedagogically oriented, it may have, nonetheless, pedagogical implications for foreign language teachers, translators, textbook writers test makers and syllabus, designers. This paper may in various ways help the language teachers and learners particularly in identifying the syntactic forms and structures that have certain functions and that are different from those of other literary genres, and hence are likely to cause difficulty. Moreover, the study may be helpful to ESP practitioners who are interested in preparing ESP teaching materials based on the analysis of authentic texts and concerned with syntactic features as well as with functions and meanings which are conveyed by syntactic structures.

Through my own experience, I do believe that both professors of linguistics and literature should give their students the opportunity to read aloud and linguistically analyze some poems inside the classroom. I. A. Richards (1960) states that the primary aim of teaching poetry is "just to help us to read better" (14). In this line of argument, William C. Morse and G. Max Wingo (1962) assert that "Reading is an ideal activity for motivation which not only instigates behavior but also operates to reinforce ongoing behavior" (3). Moreover, Sharma (2009) 
states that "There are grounds to believe that a linguistically oriented analytical approach can ensure the kind of motivation" (130). Another advantage is "transfer of learning". The student can employ his knowledge of grammar and linguistics to the poetry classes. This will encourage students (to) participate and be involved since they are expected to analyze the form and discover the poetic meaning and effect of linguistic structure. Michael Roberts (1990) states, "Poetry is primarily an exploration of possibilities of language" (3).

Another point which is worth noting in this context, is the fact that the semantic and grammatical composition of the title must be carefully studied. The student must explore all the meanings of the title and all types of meaning; referential, affective, stylistic....etc. Once the title is revealed, the poem regains its coherence and beauty. I .A. Richards (1960) insists on paying attention to the title saying that the title has "a great deal to do with the poem". (13)

\section{References}

Abrams, M. (1979). The Norton Anthology of English Literature. New York, London: W.W. Norton \& Company.

Brook, G. (1958). A History of the English Language. London: Andre Deutsch Ltd.

Culler, J. (2002). Structural Poetics: Structuralism, Linguistics and the Study of Literature. London and New York: Routledge of Kegan Paut.

Cureton, R.D. (1980b). He Danced His Did: An Analysis. Journal of Linguistics. 16, 245-62. http://dx.doi.org/10.1017/S0022226700006575

Dillon, George. (1975). Inversion and Deletion in English Poetry. Language and Style, Vol. 8, 2002-37.

------, (1996). Literary Transformation and Poetic Word Order. Poetics, 1-22.

Dixon, James. (1976). T.S. Eliot's "Journey of the Maji." [Online] Available: http://itech.fgcu.edu/faculty/wohlpart/alra/eliot.htm

Halliday, M.A.K. (1985). An Introduction to Functional Grammar. London: Edward Arnold.

Halliday, M.A.K. and R. Hasan. (1976). Cohesion in English. London: Longman.

Hilligoss, Emily. (1988). Fragmentation in the Waste Land: Why T.S. Eliot Tears Down London Bridge. [Online] Available: http://core-relation.unchicago.edu/vol.3/Hilligoss.html

Jeffries, Lesley. (1993). The Language of Twentieth-Century Poetry. London: The Macmillan Press Ltd.

Johnston, Ian. (1999). Lecture on T. S. Eliot's "The Love Song of J. Alfred Prufrock" and "The Waste Land. [Online] Available: http://www.mala.bc.ca/johnstoi/introser/eliot,html

Katz, Seth. (1997). The Poetic Use of Sentence Fragments. [Online] Available: http://www.eiu.edu/ ipaweb/pipa/volume/katz.htm

Lado, R. (1957). Linguistics across Cultures. University of Michigan Press: Ann Arbor.

Lancashire, lan. (2002). Glossary of Poetic Terms. [Online] Available: http://www.chass.utoronto.ca/ ian/glossary

Leech, Geoffrey. (1969). A Linguistic Guide to English Poetry. London \& New York: Longman.

Levin, Samuel. (1969). Linguistic Structure in Poetry. The Hague: Mouton.

Morse, William C. and G. Max Wingo. (1970). Psychology and Teaching, 3rd ed. Bombay: Tara Porevak.

Partridge, A.C. (1976). The Language of Modern Poetry: Yeats, Eliot, Auden. London: Andre Deutsch Ltd.

Quirk, R.S. Greenbaum, G. Leech and J. Svartvik. (1985). A Comprehensive Grammar of the English Language. London: Longman.

Richards, I.A. (1960). Poetic Process and Literary Analysis. Style in Language, ed. Thomas A. Sebeok Cambridge Mass: The M .I. T. Press.

Roberts, M. (1960). The Faber Book of Modern Verse. London: Faber \& Faber.

Roscow, G.H. (1981). Syntax and Style in Chaucer's Poetry. Cambridge: D.S Brewer.

Sharma, R.S. (2009). Linguistic Aspects of English Poetry. New Delhi: Sarup Book Publishers. Ltd.

Traugott, Elizabeth .C. (1972). A History of English Syntax. New York: Holt, Rinehart and Winston, Inc.

Van Dijk. T.A. (1976). Pragmatics of Language and Literature. North Holland: American Elsevier Pub. Co.

Wright, Keith. (1965). Rhetorical Repetition in T.S Eliot's Early Verse. Review of English Literature, Vol. 6, 93-100. 